\title{
Avaliação microbiológica da qualidade do pescado processado, importado no estado do Rio de Janeiro
}

\section{microbiological quality avaliation of fish meat processed and imported in Rio de Janeiro State}

\author{
Ana Lúcia Medeiros dos Santos Ribeiro, ${ }^{*}$ Gesilene Mendonça de Oliveira, ${ }^{*}$ Vanessa de Magalhães Ferreira, ${ }^{*, \star *}$ \\ Milena Marcela Domingues Pereira, ${ }^{*}$ Pedro Paulo de Oliveira Silva*
}

\begin{abstract}
Resumo
O pescado apresenta uma excelente composição química e, comparado com outros produtos de origem animal, é o que apresenta melhor digestibilidade. Atualmente o consumidor tem-se tornado mais exigente, e as indústrias vêm buscando se adequar a essa nova realidade. O presente trabalho teve como objetivo fornecer, ao Serviço de Vigilância Agropecuária, subsídios para atuar na defesa da saúde do consumidor e, aos empresários, dados para avaliação das condições de higiene e implementação de melhorias na qualidade dos produtos fabricados ou comercializados. Para tal, foram realizadas análises microbiológicas, oriundas de 11 indústrias, em amostras de peixes congeladosdefumados e salgados comercializados no estado do Rio de Janeiro, durante sete meses do ano de 2003. Com relação à análise microbiológica do peixe defumado, uma das amostras apresentou resultados fora dos padrões para Staphylococcus coagulase positiva e para coliformes termotolerantes, configurando ser produto impróprio para o consumo humano. Todas as demais amostras de peixe defumado, congelado e salgado analisadas apresentaram resultados satisfatórios para as análises microbiológicas realizadas, estando o alimento em conformidade com os padrões estabelecidos pela ANVISA, o que indica que o processamento realizado por estas indústrias foi adequado, com exceção de uma indústria que comercializa pescado defumado. Sendo assim, ao final do processo, o pescado apresentava-se dentro dos padrões nacionais indicadores de qualidade microbiológica.
\end{abstract}

Palavras-chave: qualidade do pescado, análise microbiológica, pescado processado.

\begin{abstract}
Fish meat presents an excellent chemical composition and presents better digestibility when compared to another products from animal origin. Currently consumers are becoming more demanding and industries are trying to fit themselves to this new reality. The present work was undertaken to supply the Service of Farming Monitoring with subsidies to act in the defense of consumer's health and, industries owners with information to evaluate hygienic conditions and carry on improvements in the products manufactured or commercialized. Therefore, microbiological monitoring was carried out in samples of frozen, cured and salty fish deriving from eleven industries and commercialized in Rio de Janeiro State during seven months of 2003. Microbiological analysis of cured fish samples showed that one of this are out of standards for Staphylococcus positive coagulase and fecal coliform, so it was improper for human consumption. All of other samples of cured, frozen and salty fish have presented satisfactory results for the microbiological analyses, being the same ones in accordance to the standards established by ANVISA, what indicates that processing accomplished by these industries was convenient, except in this one that commercialize cured fish. Consequently, at the processes ending fish meat was presented within the standards.
\end{abstract}

Keywords: fish meat quality, microbiological analysis, processed fish.

\section{Introdução}

Há muito tempo que o pescado faz parte da dieta alimentar do homem e em vários países constitui a principal fonte de proteína de origem alimentar (Huss, 1997). Apresenta uma excelente composição em aminoácidos, abundância em vitaminas e sais minerais e é, dentre os produtos de origem animal, o que apresenta melhor digestibilidade (Vieira et al., 2000).

Estas características do pescado atendem a uma tendência mundial de se consumir alimentos que não apenas forneçam

* Laboratório de Toxinas Marinhas, Departamento de Tecnologia de Alimentos, Universidade Federal Rural do Rio de Janeiro. Rodovia BR 465 Km7 Campus Universitário, Seropédica, RJ, CEP: 23890-000.

** Faculdade de Oceanografia, Universidade Estadual do Rio de Janeiro. Av. São Francisco Xavier, 524, $4^{\circ}$ andar, sala 4023, Maracanã, RJ, CEP 20550-013.

Autor para correspondência. E-mail: anaribeiro.toxmar@gmail.com 
nutrientes, mas, de alguma forma, tragam benefícios à saúde da população. O Brasil vem seguindo esta tendência mundial; por isso, hoje se tem a preocupação de disponibilizar à população uma carne mais saudável e que mantenha o alto valor proteico (Pacheco et al. 2004).

Embora apresente tais pontos positivos, o pescado é um dos alimentos mais suscetíveis à deterioração devido à atividade de água elevada, à sua composição química, que varia em função da espécie, às condições em que ocorre o seu consumo e à época do ano em que é capturado, assim como por causa do teor de gorduras insaturadas facilmente oxidáveis, e principalmente, do $\mathrm{pH}$ próximo da neutralidade, favorecendo o desenvolvimento microbiano (Barros, 2003; Landgraf, 1996; Nickelson II et al., 2001). Entre os processos que podem levar à deterioração do pescado há: a ação de enzimas autolíticas, a autoxidação lipídica e a atividade bacteriana. De todos, os micro-organismos constituem os principais responsáveis pelo surgimento das alterações (Burgess, 1978). O pescado pode atuar como potencial veiculador de micro-organismos patogênicos para o homem, como as bactérias Staphylococcus coagulase positiva (Aquino et al., 1996; Dams et al., 1996; Hiluy et al., 1996), Escherichia coli, Salmonella spp., Costridium perfringens, entre outros (Ahmed, 1991; Gonçalves Hernandes, 1998; Hoffman et al., 1999; Farias et al. 2007). A presença desses micro-organismos evidencia deficiências em algumas etapas do processamento ou na conservação do produto final, que comprometem a qualidade e o grau de frescor, podendo causar sérios danos à saúde do consumidor, que vão desde uma simples intoxicação até a morte (Rebouças, 2005). Uma fonte de contaminação importante é a manipulação do pescado, desde o momento da captura, ainda nos barcos pesqueiros (Zican, 1994; Martins et al., 2002, Lee et al. 2004), até sua destinação final após passar por inúmeras fases de processamento e transporte (Cardonha et al., 1994). Outro fator que corrobora para a ocorrência deste tipo de contaminação é a deficiência no processo de sanitização dos equipamentos de processamento (Bennett, 2003).

Atualmente o consumidor tem-se tornado mais exigente, e as indústrias vêm buscando atender a essa nova realidade, investindo na qualidade de seus produtos. Essa qualidade deverá assegurar ao consumidor produtos que satisfaçam suas necessidades e, ao mesmo tempo, sejam seguros (Pacheco et al., 2004).

Objetivando fornecer ao Serviço de Vigilância Agropecuária subsídios para atuar na defesa da saúde do consumidor, assim como oferecer aos empresários condições de avaliação e implementação de melhorias na qualidade dos produtos por eles comercializados ou fabricados, realizaramse análises microbiológicas, durante sete meses do ano de 2003, em amostras de filés de peixes congelados e comercializados no estado do Rio de Janeiro: merluza (Merluccius spp.) e salmão (Salmo salar), peixes defumados, salmão e hadoque (Melanogrammus aeglefinus) e peixes salgados, bacalhau do porto (Gadus morhua) e bacalhau saithe (Pollachius virens). Todas essas amostras são oriundas de 11 indústrias e foram avaliadas segundo a resolução da diretoria colegiada no 12/2001 da ANVISA.

\section{Material e métodos}

\section{Amostragem}

No período de janeiro a julho de 2003, foram obtidas 74 amostras (62 de peixe congelado, dez de peixe defumado e seis de peixe salgado), baseado no fluxo de entrada de amostras de pescado processado no Laboratório de Análises de Alimentos e Bebidas do Maracanã - RJ (convênio UFRRJ/ MAPA). As amostras eram oriundas de coletas realizadas pelo Ministério da Agricultura, Pecuária e Abastecimento (DFARJ; SVA e SIPA) em 11 indústrias de pescado.

\section{Análises microbiológicas}

As amostras de peixe congelado foram previamente descongeladas no refrigerador a uma temperatura que variou entre $8^{\circ} \mathrm{C}$ e $5^{\circ} \mathrm{C}$ durante um tempo máximo de 18 horas. Todas as análises foram realizadas de acordo com as instruções da American Public Health Association (APHA, 1992).

\section{Contagem, isolamento e identificação de Sthaphylococcus coagulase positiva}

Utilizaram-se alíquotas de $25 \mathrm{~g}$ de cada amostra de peixe, às quais foram adicionados $225 \mathrm{~mL}$ de solução salina peptonada $0,1 \%$. Fez-se a homogeneização e prepararamse as diluições decimais.

Foi semeado sobre superfície de ágar Baird-Parker, em duplicata, $0,1 \mathrm{~mL}$ da diluição $10^{-1}$ e da diluição $10^{-2}$. Com auxílio de alça de Drigalski, o inóculo foi cuidadosamente espalhado por toda a superfície do meio até a total absorção. Posteriormente, as placas foram incubadas a $37^{\circ} \mathrm{C}$ por 24 48 horas. Após a incubação, colônias típicas pequenas, pretas, brilhantes, lisas, convexas e com halo transparente foram contadas e submetidas às provas de produção das enzimas catalase e coagulase.

\section{Pesquisa de Salmonella spp.}

A partir de $25 \mathrm{~g}$ de cada amostra de peixe adicionada a $225 \mathrm{~mL}$ de água peptonada $1 \%$ tamponada, representando a diluição $10^{-1}$, procedeu-se à homogeneização e posterior incubação a $35^{\circ} \mathrm{C}$ por $18-20$ horas com a finalidade de pré-enriquecimento. Para o enriquecimento seletivo, $1 \mathrm{~mL}$ de cada solução de pré-enriquecimento foi transferido para tubos de ensaio, contendo $10 \mathrm{~mL}$ de caldo selenito cistina que foram incubados a $35^{\circ} \mathrm{C}$, e caldo Rappaport Vassiliadis que foi incubado em banho-maria a $45^{\circ} \mathrm{C}$, ambos por 24 horas. Para o isolamento, foram realizadas estrias em ágar verde brilhante vermelho de fenol lactose sacarose (BPLS) e em ágar Salmonella-Shigella (ASS) incubados a $35^{\circ} \mathrm{C}$ por 24 horas. Após a incubação, verificou-se o desenvolvimento de colônias típicas. No BPLS, colônias incolores/rosadas, entre translúcidas ou levemente opacas, e, no ASS, as colônias apresentaram-se translúcidas, de bordas regulares e transparentes com centro preto.

Foram transferidas três colônias típicas para ágar nutriente inclinado que foram incubadas a $35^{\circ}$ por 24 horas. A partir de cada tubo de ágar nutriente isolaram-se colônias em Ágar Triplo Sugar Iron (TSI) e Lisine Iron Agar (LIA) por picagem em profundidade e estrias superficiais, incubando-as a $35^{\circ}$ 
por 24 horas. A partir dos tubos com identificação presuntiva, em TSI formação de gás, base amarelada e produção de $\mathrm{H}_{2} \mathrm{~S}$ (preto) no local da picada, em LIA, meio violeta e produção de $\mathrm{H}_{2} \mathrm{~S}$ (preto) no local da picada, procedeu-se à sorologia $\mathrm{O}$ e $\mathrm{H}$, considerando esta positiva quando da aglutinação em ambos.

\section{Determinação de Número Mais Provável (NMP) de coliformes totais e termotolerantes}

Foram utilizadas alíquotas de $25 \mathrm{~g}$ de cada amostra de peixe, as quais foram adicionadas a $225 \mathrm{~mL}$ de água peptonada $0,1 \%$. Fez-se a homogeneização e prepararam-se as diluições $10^{-1} \mathrm{e} 10^{-2}$. Para os testes presuntivos foram inoculados, em série de três tubos contendo caldo lauril sulfato lactose, $1 \mathrm{~mL}$ de cada diluição. Após terem sido estes incubados a $35^{\circ} \mathrm{C}$ por 48 horas e verificada a presença de gás nos tubos de Durhan, procederam-se testes confirmativos.

Para confirmação de coliformes totais, foi transferida uma alçada de cada tubo positivo para tubos contendo caldo verde brilhante bile $2 \%$ lactose, incubando-os a $35^{\circ} \mathrm{C}$ por 48 horas. Para confirmação de coliformes fecais, foi transferida uma alçada de cada tubo positivo nas análises presuntivas para tubos contendo caldo EC. Incubou-se a $45^{\circ} \mathrm{C}$ em banho-maria com circulação de água, por 48 horas. A confirmação da presença de coliformes totais e termotolerantes é feita pela presença de gás nos tubos de Durhan e turvação do meio.

\section{Resultados e discussão}

Foram analisadas 62 amostras de pescado congelado, oriundas das indústrias A, B, C, D, E e F. Os resultados para Staphylococcus coagulase positiva para todas as amostras foi de menos de 100 unidades formadoras de colônias por grama (Tabela 1).

Tabela 1: Resultado das análises realizadas para evidenciação de Salmonella e Staphylococcus coagulase positiva, em pescado congelado, defumado e salgado; Coliformes termotolerantes, em pescado defumado e salgado; Coliformes totais em pescado defumado

\begin{tabular}{cccccc}
\hline Indústria & $\begin{array}{c}\text { № de } \\
\text { amostras }\end{array}$ & $\begin{array}{c}\text { Staphylococcus } \\
\text { coagulase } \\
(\text { UFC/g })\end{array}$ & Salmonella & $\begin{array}{c}\text { NMP de } \\
\text { Coliformes } \\
\text { Totais }\end{array}$ & $\begin{array}{c}\text { NMP de } \\
\text { Coliformes } \\
\text { Termotolerantes }\end{array}$ \\
\hline A & 4 & $<1,0 \times 10^{2}$ & ausência & - & - \\
B & 4 & $<1,0 \times 10^{2}$ & ausência & - & - \\
C & 9 & $<1,0 \times 10^{2}$ & ausência & - & - \\
D & 2 & $<1,0 \times 10^{2}$ & ausência & - & - \\
E & 30 & $<1,0 \times 10^{2}$ & ausência & - & - \\
F & 13 & $<1,0 \times 10^{2}$ & ausência & - & - \\
G & $3 / 4$ & $<1,0 \times 10^{2}$ & ausência & $<0,3$ & $<0,3$ \\
G & $\mathbf{1} / \mathbf{4}$ & $\mathbf{1 , 0 \times 1 0 ^ { 3 }}$ & ausência & $\mathbf{4 , 6}$ & $\mathbf{4 , 6}$ \\
H & 1 & $<1,0 \times 10^{2}$ & ausência & $<0,3$ & $<0,3$ \\
I & 1 & $<1,0 \times 10^{2}$ & ausência & $<0,3$ & $<0,3$ \\
J & 4 & $<1,0 \times 10^{2}$ & ausência & - & $<0,3$ \\
L & 2 & $<1,0 \times 10^{2}$ & ausência & - & $<0,3$ \\
\hline
\end{tabular}

Uma das amostras de pescado defumado oriunda da indústria $\mathrm{G}$ apresentou 1,0 × $10^{3} \mathrm{UFC} / \mathrm{g}$ de Staphylococcus coagulase positiva e para coliformes totais e termotolerantes $4,6 \times 10^{2} \mathrm{NMP} / \mathrm{g}$ (Tabela 1), configurando ser o mesmo impróprio para o consumo humano conforme a RDC № 12 da ANVISA.

As demais amostras de pescado defumado oriundas das indústrias G, H e I apresentaram ausência de Salmonella em $25 \mathrm{~g}$ de amostra e resultados inferiores aos estabelecidos pela legislação para as análises de Staphylococcus coagulase positiva e para coliformes termotolerantes (Tabela 1), encontrando-se os mesmos em conformidade com os padrões estabelecidos pela Resolução oㅡ 12, de 02/01/01 da ANVISA.

As seis amostras de pescado salgado, oriundas das indústrias $\mathrm{J}$ e $\mathrm{L}$, estavam em conformidade com os padrões microbiológicos estabelecidos pela resolução ํo 12, de 02/01/01 da ANVISA, uma vez que apresentaram resultados inferiores aos estabelecidos pela legislação para as análises de Staphylococcus coagulase positiva, pesquisa de Salmonella spp. e para coliformes termotolerantes (Tabela 1).

No presente estudo, foi verificada a ausência de Salmonella em todas as análises realizadas, nas amostras de pescado congelado, defumado e salgado. Resultados semelhantes foram encontrados por Farias et al. (2007) ao avaliar a qualidade microbiológica de pescado beneficiado no estado do Pará. Esses resultados vêm de encontro ao que afirmou Ahmed (1991), segundo o qual o pescado é um veículo de Salmonella spp. muito menos frequente do que outros produtos alimentares, sendo o peixe e os mariscos responsáveis apenas por uma pequena percentagem do número total de casos de Salmonella spp. referidos nos Estados Unidos e em outros países. Porém a ausência de Salmonella contrastou com os resultados obtidos por Gonçalves e Hernandez (1998), Hoffman et al. (1999), que observaram a ocorrência deste micro-organismo, respectivamente, em $80 \%$ de filé de peixe congelado e $40 \%$ de peixe inteiro congelado.

Os resultados obtidos nas análises do pescado congelado e salgado para Staphylococcus coagulase positiva indicaram que o mesmo se encontrava em conformidade com os padrões estabelecidos pela Resolução no 12 , de 02/01/01 da ANVISA. Esses dados foram inferiores aos encontrados por Aquino et al. (1996), em pescado congelado, na cidade de Manaus, e por Dams et al. (1996) em filés de peixe em Santa Catarina. Hiluy et al. (1996), avaliando 22 amostras de produtos pesqueiros (peixes, ostras e camarões), verificaram a ocorrência de $S$. aureus em $50 \%$ das amostras de camarão e $20 \%$ das amostras de peixe. De acordo com Landgraf (1996), os resultados obtidos no presente estudo indicam que houve uma manipulação adequada dos mesmos durante o processamento, uma vez que se acredita ser o manipulador o principal veiculador destes micro-organismos que se alojam preferencialmente nas fossas nasais, boca e pele. 
As indústrias $\mathrm{H}$ e I de pescado defumado apresentaram resultados satisfatórios, porém uma das amostras oriundas da indústria $\mathrm{G}$ apresentou-se fora dos padrões para Staphylococcus coagulase positiva, coliformes totais e termotolerantes. Estes resultados indicam uma provável falha durante o processamento realizado nesta indústria. Vieira et al. (2000) constataram que, ao longo das etapas de processamento de filés de tilápia na Paraíba, as cifras para $S$. aureus flutuaram entre o valor estimado de $<10,0$ a 10,6 x 10² UFC/g, indicando um aumento crescente da contami-nação. Segundo Martins et al. (2002), a presença de bactérias coliformes é considerada indicativo de contaminação por dejetos orgânicos e evidencia possível contaminação por bactérias patogênicas. Este autor encontrou uma variação de $<10$ a 1,2 × $10^{4}$ para coliformes fecais, o que foi um resultado inferior ao obtido no presente trabalho.

Rebouças (2005) afirma que a manipulação inadequada representa um risco potencial, pois, a partir desta etapa, micro-organismos patogênicos tais como Streptococcus spp. e Staphylococcus aureus, ambos de origem humana, podem contaminar o pescado. Bennett (2003) argumenta que $S$. aureus é vulnerável a tratamento térmico, bem como ao tratamento com a maioria dos agentes de limpeza. Assim, sua presença em alimentos processados ou em equipamentos de processamento é geralmente um indicativo de sanitização inadequada.

\section{Referências}

AHMED, F.E.(Ed.), 1991. Seafood safety. National Academy Press, Washington D.C., USA.

ANVISA, Resolução RDC № 12, de 2 de janeiro de 2001 - Aprova o regulamento técnico sobre padrões microbiológicos para alimentos. Disponível em: <www.agricultura.gov.br>.

APHA-AMERICAN PUBLIC HEALTH ASSOCIATION. Compendium of methods for biological examination of foods. 3. ed. Washington, Americam Public Heath Association, 1992. 1219 p.

AQUINO, J.S.; VASCONCELOS, J.C.; INHANUMS, A.J.; SILVA, M.S.B. Estudo microbiológico de pescado congelado comercializado em Manaus (AM). Boletim do Centro de Pesquisa e Processamento de Alimentos, v. 14, n. 1, p. 78-82, 1996.

BARROS, G. C. Perda de qualidade do pescado, deteriora e putrefação. Revista CFMV, ano IX, no 30, p. 59-64, 2003.

BENNETT, R.W. Staphylococcus aureus. In: VIEIRA, R.H.S.F. Microbiologia e qualidade do pescado: teoria e prática. São Paulo: Varela, p. 96, 2003.

BURGESS, G.H.O. El pescado y las industrias derivadas de la pesca. Ed. Acribia. Zaragoza. España. 1978.

CARDONHA, A.M.S.; CASIMIRO, A.R.S.; VIEIRA, R.H.S. F. Identificação de bactérias psicotróficas em caudas de lagosta, durante processo industrial com tripolifosfato de sódio. Rev. Higiene Alimentar, v. 8, n. 31, p. 29-34, 1994.

DAMS, R.I.; RIBEIRÃO, L.H.; TEIXEIRA, E. Avaliação da qualidade microbiológica da pescadinha (Cynoscion striatus) inteira e em filé nos principais pontos críticos de controle de uma indústria de pescado congelado. Boletim do Centro de Pesquisa e Processamento de Alimentos. v. 14, n. 2, p. 151-162, 1996.

FARIAS, M. do C.A.; MOURA, C.S.A.F.; FREITAS, J. de A. Qualidade microbiológica do pescado beneficiado por indústrias no estado do Pará. Rev. Higiene Alimentar, v. 21, n. 150, p. 254, 2007.

GONÇALVES, A.; HERNANDEZ, C.P. Defumação líquida de anchova (Pomatus saltatrix): efeitos do processamento nas prorpiedades químicas e microbiológicas. Rev. Ciência e Tecnologia de Alimentos, São Paulo, v. 18, n. 4, p. 438-443, 1998.
Pessoas que trabalham na área de beneficiamento de produtos pesqueiros, muitas vezes, são responsáveis pela contaminação microbiológica desses alimentos, sem que tenham consciência, na maioria das vezes, do seu papel como veículo de contaminação. Lee et al. (2004) acreditam que a maioria dos surtos veiculados por alimentos, na Coréia e no Japão, no período de 1981 a 1995, foram causados devido à manipulação inadequada dos alimentos.

\section{Conclusões}

Os pescados processados (filé de merluza, salmão congelado, peixe defumado e peixe salgado) adquiridos no período de janeiro a julho de 2003 e comercializados pelas indústrias $A, B, C, D, E, F, G, H, I, J$ e L, com exceção de um lote da empresa $G$ (pescado defumado), foram encaminhados para o comércio, pois os mesmos se encontravam em conformidade com a resolução no 12 , de 02/01/2001 da ANVISA.

Os resultados obtidos puderam fornecer subsídios ao Serviço de Vigilância Agropecuária no Porto/Aeroporto/Postos de Fronteira/SIPA para atuarem na defesa da saúde do consumidor, assim como ofereceram às indústrias processadoras parâmetros de avaliação para implementação de melhorias, quando necessárias, na qualidade dos seus produtos.

HOFFMAN, F.L.; GARCIA-CRUZ, C.H.; VINTURIM, T.M. et al. Levantamento da qualidade higiênico-sanitária do pescado comercializado na cidade de São José do Rio Preto, SP. Rev. Higiene Alimentar, v. 14, n. 64, p. 45-47, 1999.

HILUY, D. J.; PINHEIRO, H.C.G.; MOURÃO, A.F.; MACEDO, E.P.; CARVALHO, M.L.M.; PINTO, A. Avaliação da qualidade dos produtos pesqueiros no estado do Ceará. Rev. Higiene Alimentar, São Paulo, v. 10, n. 45 , p. 37. 1996.

HUSS, H.H. Garantia da qualidade dos produtos da pesca. FAO Documento técnico sobre as pescas, n 3․ Raoma:FAO, 1997. 176 p. LANDGRAF, M. Deterioração microbiana de alimentos. In: Franco, B.D.G.; Landgraf, M. Microbiologia dos alimentos. São Paulo: Editora Atheneu. 182 p. cap. 6, p. 93-108, 1996.

LEE, W. C.; LEE, M. J.; KIM, J. S.; PARK, S. Y. Staphyloccocus aureus. In Vieira, R.H.S.F. Microbiologia, Higiene e qualidade do pescadoteoria e prática. São Paulo: Varela Editora, p. 380, 2004.

MARTINS, C.V.B., VAZ, S.K., MINOZZO, M.G. Aspectos sanitários de pescados comercializados em pesque-pagues de Toledo-PR. Rev. Higiene Alimentar, São Paulo, v. 16, n. 98, p. 51-56, 2002.

NICKELSON II, R; MACCARTHY, S; FINNE, G. Fish, crustaceans and precooked seafoods. In:Compendium of methods for the microbiological Examinations of Foods. 4. ed. APHA, 2001. cap. 48, p. 497-505.

PACHECO, T.A.; LEITE, R.G.M; ALMEIDA.A.C; SILVA, N. M. O; FIORINI, J,E. Análise de coliformes e bactérias mesofílicas em pescado de água doce. Rev. Higiene Alimentar, v.18, n. 116/117, p. 68-72, 2004. REBOUÇAS, R.H. Staphylococcus coagulase positiva em camarão marinho sete-barbas (Xiphopenaeus kroyeri) comercializado na feira-livre de pescado do Mucuripe. monografia. Universidade Federal do Ceará, 2005.

VIEIRA, K.V.M.; D.C.C.;JANEBRO, D. I.; VIEIRA, R.H.S.F.; CEBALLOS, B.S.O. Influência das condições higiênico-sanitárias no processo de beneficiamento de tilápias (Oreocrhomis niloticus) em filés congelados. Rev. Higiene Alimentar, São Paulo, v. 14, n. 74, p. 17-40. 2000 .

ZICAN, C.A. O Ministério da Agricultura iniciou o controle sanitário através do sistema de pontos críticos. O pescado é o carro chefe desse sistema. Rev. Higiene Alimentar, v. 8, n. 31, p. 9-10, 1994. Apresentado no 1ำ Seminário de Vigilância Sanitária Pesqueira: Qualidade dos Pescados, 1994, São Paulo. 